\title{
The Moderating Effect of Socio-Demographic Characteristics on Subjective Wellbeing
}

\author{
Olusegun Mayungbo (Corresponding author) \\ Department of Sociology and Psychology, Faculty of Social and Management Sciences \\ Lead City University Ibadan, Nigeria
}

Tel: 0813-617-4435Ｅ-mail: doctormayungbo@gmail.com

Received: January 4, 2017 Accepted: March 16, 2017 Published: March 29, 2017

doi:10.5296/ijssr.v5i1.11009 URL: http://dx.doi.org/10.5296/ijssr.v5i1.11009

\begin{abstract}
The independent association between socio-demographic characteristics and subjective well-being is well studied, however, the moderating impact of those characteristics are yet to be established in literature. This study examines the moderating influence of socio-demographic characteristics on subjective well-being among residents in Ibadan metropolis. Using a descriptive survey design and a multistage sampling technique, 10 enumeration areas each were selected from the five major Local Government Areas (LGAs) with simple random technique. The number of participants on the selected enumeration areas were determined with enumeration area maps. Two hundred and twenty participants each were selected from each LGA, using a systematic technique, making a total of 1,100 participants. A questionnaire focusing on socio-demographic profile and life satisfaction scale $(\mathrm{r}=0.74)$ was administered to the participants. Data were analyzed using descriptive statistics, co-relational analysis, moderated hierarchical multiple regression and analysis of variance at 0.05 level of significance. Two hypotheses were tested. The result reveals that socio-demographic factors jointly predicted life satisfaction $(F(1,1007)=4.61, p<.001)$. Age and marital status also interacted to predict life satisfaction $(\beta=-0.13, \mathrm{t}=-3.58, \mathrm{p}<.01 ; \beta=$ $-0.08, \mathrm{t}=1.98, \mathrm{p}<.05)$. The interaction effect of social demographic factors should be considered in a comprehensive examination of subjective wellbeing.
\end{abstract}

Keywords: Subjective wellbeing, Socio-demographic characteristics, Enumeration areas, Moderation,

\section{Introduction}

Subjective well-being, also known as life satisfaction or happiness or quality of life 
(Veenhoven, 2009) has been widely studied in psychology and other disciplines. However, studies of subjective wellbeing from different disciplines have recorded different findings across nations (Veenhoven, 1993). This suggests that the association between subjective well-being and its determinants varies from place to place. In an attempt to predict subjective wellbeing, some recent studies in Nigeria have mainly focused on psychological factors (Oladipo \& Olapegba, 2012), emotional intelligence and social support (Kolade \& Dennis, 2015), personality factors (Mayungbo,2016) etc. These studies have sometimes reported different and conflicting results. This is an indication that the determinants of subjective wellbeing are not universal but vary with culture, time and place (Nordbakke \& Schwanen 2013). Only few studies have considered the influence of socio-demographic factors on subjective wellbeing among Nigerian population and even the few foreign studies that have done so, have focused on only one or two factors at a time i.e age and subjective well-being (Ulloa, Møller, \& Sousa-Poza, 2013), gender and happiness (Zweig, 2015) and so on. There are only few studies that have directly examined the moderating effect of multiple socio demographic characteristics on subjective wellbeing among Nigerian samples. As observed by Agbo, Nzeadibe and Ajero (2012), there are limited studies on the correlates of life satisfaction of Nigerians. The purpose of this paper is to examine the moderating influence of age, gender, marital status and educational qualification on subjective wellbeing.

Research on the study of the relationship between subjective wellbeing and age have produced conflicting results. While some findings have found no relationship, other studies have reported a positive association. Old age is usually associated with reduction in human health and quality of life (Bond \& Corner, 2004). Yet, some findings have indicated that subjective well-being is either stable or increasing as individuals attain old age (Blanchflower \& Oswald, 2008; Frijters \& Beatton, 2012).Cross-sectional studies from various cultures also conclude that life satisfaction is relatively stable across age groups in most countries (Schilling, 2006; Baird, Lucas, \& Donnellan, 2010; Hansen \& Slagsvold, 2011). Three suggestions were offered for individuals reporting high subjective wellbeing in old age. The first is the influence of personality and adaptation (Diener \& Suh, 1998). It is assumed that even if life circumstances alter subjective wellbeing for a while, individuals would return to their baseline level over time, based on their personality traits. The second explanation suggests that the elderly seems to reduce their needs, aspirations and standard of comparison (George, 2006) and the reduction is believed to promote well-being by reducing the aspirations and achievement gaps among the elderly than the middle-aged adults (Cheng, 2004). The third explanation relates to the experiences and competencies of the elderly to regulate their emotions.

In the views of Carstensen (1991) human social goals change with age. As individuals advance in age, their desire to relate with friends and acquaintances and the satisfaction derived from such relationships decrease. Therefore old people selectively reduce their social networks and focus their time on emotionally intimate social relationships, such as close friends and family. Bowling (2011) asserts that compared to people below the age of 65, individuals above the age of 65 report having a smaller number of individuals to turn to for physical and emotional support during difficult times. However, it is not clear whether the 
smaller number of individuals available in the social network is due to old people's choice or to their circumstances. Whatever the reason, the decline in social relationship and social goals suggest there may be age differences in how people report their social support experiences and their life satisfaction. It is clear that social relationship is an important aspect of life satisfaction in old age.

Gender differences in subjective wellbeing are not generally found to be in the support of women. There are gender differences in many dimensions of wellbeing across the world (Klasen, 2004) which in most cases, does not favour women. Considering the time spent in unpaid care work, women seem to have longer working weeks than men (Eurofound, 2013).Women report higher score of depression than men (Tesch-Romer, Motel-Klingebiel, \& Tomasik, 2008) and they also rate their subjective health lower than men (UN World Happiness Report, 2012). Boarini, Comola, Smith, Manchin and de Keulenaer (2012) also reported the higher happiness and lower affect balance of women. Therefore, Women generally live in worse conditions than men, but Women are more satisfied with life when they are placed in the same conditions with men (Easterlin, 2003; Alesina, DiTella, \& MacCulloch, 2004; Kahneman \& Kruger, 2006; Kapteyn, Smith, \& Van Soest, 2009; Boarini et al., 2012). Graham and Chattopadyay (2013) also found that women have higher levels of wellbeing than men, with a few exceptions in low income countries, such as Sub-Saharan Africa. On the contrary, however, Moksnes and Espnes (2013) found a lower level of life satisfaction for women than men. Similarly, Goldbeck, Schmitz, Besier, Herschbach and Henrich (2007) document a lower life satisfaction for girls as compared to boys.

Research evidence has also indicated that marriage improves the level of life satisfaction, across countries. The importance of marriage has been attributed to its provision of social support (House, Landis, \& Umberson, 1988). Marriage is a social contract that binds people together in an intimate relationship that can help them cope in times of stress, marriage foster social integration and a sense of belonging and purpose to the married (Waite and Gallagher 2000). Family members are expected to provide emotionally support and are likely to contribute to well-being by providing relieve during stressful life events (Umberson \& Chen, 1994). Frey and Stutzer (2002) contend that marriage provides additional sources of self esteem, social support and companionship. Lucas (2003) suggests that individuals experience changes in life satisfaction in the year after marriage. Some people report rapid reduction in wellbeing after marriage, others return to their baseline after some years while others continue to experience increase in life satisfaction over time. Yet, almost everyone experience an increase in life satisfaction immediately after marriage. Easterlin (2003) also notes increases in life satisfaction among those who married in the first decade of adulthood. However, numerous studies have suggested that married people are more satisfied with life than the never-married or previously married people (Heliwell, 2003; Strine, Chapman, Balluz, Moriarty, \& Mokdad, 2008; Mousavi, Shiani, Mohammadi, Sadjadi, Tabatabaee, \& Assari, 2011; Sun, Chen, Johannesson, Kind, \& Burström, 2016).

Similarly, Verbakel, (2012) notes that married people are happier and more satisfied with their lives than the unmarried. The positive association between marital status and life satisfaction has also been observed by Diener, Suh, Lucas, \& Smith (1999), in several cross-sectional 
studies. These findings are in line with the generally held believe that, marriage can directly enhance personal well-being by providing emotional and financial support. According to Carr and Springer (2010), the influence of marriage for physical and emotional wellbeing of individuals are widely reported. However, recent studies have identified that the influence of marriage is dependent on the quality of the marriage. Marriages that are problematic are likely to have emotional effects on married individuals, while a high-quality marriage tend to provide benefits, especially for women (Proulx, Helms, \& Buehler, 2007) and older adults (Umberson, Williams, Powers, Liu, \& Needham, 2006). The married tend to ignore problems with their spouses because the relationship is an important source of emotional closeness and intimacy (Luong, Charles, \& Fingerman, 2011). Recent empirical research however suggests that in marriage, the husband's health has numerous effects on the wife's wellbeing while the wives' health does not have comparable effects on the husband's satisfaction with life (Iveniuk, Waite, Laumann, McClintock, \& Tiedt, 2014),

Researchers have identified a little relationship between education and life satisfaction. However, the relationship seems to disappear when income and occupation are statistically controlled. In other words, the relationship between education and life satisfaction is probably due to the fact that higher levels of education are related to higher incomes. Cuñado and de Gracia (2012) suggest that education has direct and indirect means of influencing individual well-being. The direct means refers to the increased self-confidence that higher education provides, while the indirect means are related to the opportunities of quality jobs, income, etc. that it provides. Education also appears to be more highly related to life satisfaction for individuals with lower incomes and in poor countries. Probably, poor individuals obtain better life satisfaction from education because the achievement is beyond their expectations. Blanchflower \& Oswald (2011) and Helliwell (2008) suggest that education has a positive association with life satisfaction. Diener, Diener, and Diener (1995) found that higher education was a significant predictor of life satisfaction. In investigating demographic data and life satisfaction, it has been reported that higher education tends to lead towards higher life satisfaction. On the contrary however, the well educated are reported to be slightly less satisfied with life in the developed countries (Veenhoven, 1994). This phenomenon is commonly explained in terms of relative deprivation, the well educated expecting more than they get.

Evidently, numerous studies had been previously conducted on the relationship between subjective well-being and demographic factors. However, past findings were not conclusive and besides, only a few of the studies were conducted among Nigerian samples. Against this background, the following research questions are raised: Will age, gender, marital status and educational qualification independently and jointly predict life satisfaction? Will age,gender,marital status and educational qualification interact to predict life satisfaction? One major contribution of this study would be the implication of its findings for the assessment of individuals on life satisfaction.

The following hypotheses would be tested; 
1) Age, gender, marital status and educational qualification will significantly jointly and independently predict life satisfaction.

2) Age, gender, marital status and educational qualification will significantly interact to predict life satisfaction

\section{Research Methods}

\subsection{Design}

The study is a descriptive survey. The independent variables in the study are: age (at 4 levels; 16-19,20-29,30-45,46-60, and above 60), gender (at 2 levels; male \& female), marital status (at 5 levels; never married, married, separated, divorced and widowed) and educational qualification (at 4 levels; no formal education, primary education, secondary education and tertiary education). The dependent variable is subjective wellbeing.

\subsection{Sampling Procedure}

A multistage sampling method was adopted for the study. The first stage involves obtaining the list of all Local Government Areas (LGAs) in Ibadan metropolis from the Ministry of Lands and Housing and selecting the five major LGAs from the existing eleven LGAs, using purposive sampling method. The second stage involves obtaining the list of enumeration areas (EAs) for the selected five major LGAs in Ibadan metropolis from the National Population Commission (NPC). The researcher randomly selected 50 EAs i.e. ten EAs from each Local Government Area (LGA) by assigning numbers to the enumeration area (EA) names, calculated the sample fraction, randomly selected the first EA and finally selected every nth on the list for the remaining EAs, based on the sample fraction. Stage three was the point at which the EA maps for the selected areas were obtained from the National Population Commission to determine the number of houses and their locations in the selected EAs in each of the LGAs. The fourth Stage involves random selection of households among the identified houses from each EA by picking and marking every other household or balloting to select a household where there are blocks of flats. The last Stage was the sampling of all heads of households residing in the marked houses.

\subsection{Participants}

220 participants were sampled in each LGA, making a total of 1100 participants. Participants consisted of house-owners and renters drawn from the high, low and medium density areas of the five major Local Government Areas (LGAs). The participants' age range was $42.11 \pm 15.20$ years. $443(43.8 \%)$ of the participants were males while $569(56.2 \%)$ were females. Participants' educational qualification was $9.9 \%$ no formal education, $23.7 \%$ primary education, $29.9 \%$ secondary education and 36.5 tertiary education. Participants' marital status was $79.6 \%$ married, $1.7 \%$ separated, $0.27 \%$ divorced, $4.9 \%$ widowed and $13.5 \%$ never married.

\subsection{Research Instrument}

The main instrument for data collection for this research was a structured questionnaire 
which consists of two sections: A and B.

2.4.1. Section A: consists of the social demographic characteristics of participants such as, age, gender, occupation, marital status, ethnic group, educational status, etc.

2.4.2. Section B: measures life satisfaction which refers to the contentment or an acceptance of one's life circumstances. It is used interchangeably with subjective wellbeing and happiness in this study. It was measured by a 20 -item scale developed by Neugarten et al. (1961). It has 3 response formats which are disagree, agree and don't know. It measures 5 domains of life such as zest for life, resolution and fortitude, congruence between desired and achieved goals, high physical, psychological and social self-concept, happy and optimistic mood tone. The 20 item has become the most used survey instrument for older adults (Helmes, Goffin \& Chrisjohn, 1998). The Cronbach alpha reported ranges from 0.79 to 0.90 . Its a three-point scoring system which rates an agree response as 2, I don't know response as 1 and a disagree response as 0 . The total score on the scale was based on participant's agreement with specific responses to individual items. Neugarten et al.(1961) obtained a mean score of 12.4 (SD, 4.4). The possible range with one point given for each agreement is $0-20$. The Cronbach alpha recorded for this study is 0.55 . The mean for this study is 19.61 . Participants who scored above the mean were categorized as being satisfied with life while those who scored below the mean were classified as not being satisfied with life.

\subsection{Research Setting}

The study took place in 50 enumeration areas or neighbourhoods across the five major Local Government Areas (LGAs) in Ibadan metropolis, South Western Nigeria.

\subsection{Procedure for Data Collection}

The researcher located the randomly selected enumeration areas or neighbourhoods within the five major Local Government Areas (LGAs) with the help of the seven experienced staff members of the National Population Commission who were the research assistants for this study. Enumeration area maps were used to identify the selected enumeration area boundaries. Having randomly selected all the houses in the selected enumeration areas, households were identified. Having identified the households, the researcher identified heads of households of each of those selected houses and presented the researcher's letter of introduction to them. The research assistants also applied their vast experience in getting the cooperation of some, initially, uncooperative participants. Participants were made to understand that the purpose of the exercise was purely academic and therefore the confidentiality of their responses was guaranteed. The researcher sought their permission to mark their houses with chalk before the commencement of the administration of questionnaires. Having agreed to participate in the study, participants were requested to sign the consent forms before the questionnaires were given to them to test the stated hypotheses. Questionnaires were administered under the condition of anonymity. Some questionnaires were completed and returned immediately, some were collected some hours later, some were collected the next day, some were collected days after while some were never returned. The delay in collection of questionnaires was partly due to the tight schedule of some respondents and the number of items involved in the 
scales. Some of the questionnaires that were either not well filled or completed were discarded. Out of the one thousand one hundred questionnaires administered, only one thousand one hundred and twelve were completed and returned. The completed copies were scored and analyzed with Statistical Package for the Social Sciences (SPSS) software.

\subsection{Statistical Analysis}

The statistical tool employed in this study were co relational analysis, moderated hierarchical multiple regression analysis and analysis of variance (ANOVA).

\section{Analysis of Results}

Table 1. The Zero-Order correlation of the relationship between age, sex, marital status and educational qualification on life satisfaction

\begin{tabular}{|c|c|c|c|c|c|c|c|}
\hline & Mean & S.D & 1 & 2 & 3 & 4 & 5 \\
\hline Life satisfaction & 19.5287 & 3.407 & 1 & $-.090^{* *}$ & -.023 & .029 & $.063^{*}$ \\
\hline Age & 42.1097 & 15.199 & & - & $-.111^{* *}$ & $.384^{* *}$ & $-.160^{* *}$ \\
\hline Sex & 1.5623 & .49635 & & & - & $.157^{* *}$ & $-.149^{* *}$ \\
\hline Marital & 2.0109 & .82065 & & & & - & $-.187^{* *}$ \\
\hline Education & 3.3261 & 1.974 & & & & & - \\
\hline
\end{tabular}

**. Correlation is significant at the 0.01 level (2-tailed).

*. Correlation is significant at the 0.05 level (2-tailed).

The zero order correlation on the relationship between age, gender, marital status, educational qualification and life satisfaction reveals that age was inversely correlated to life satisfaction $(\mathrm{r}=-.09, p<.01)$ while educational qualification was associated with life satisfaction $(\mathrm{r}=.06$, $p<.01)$. For the moderator variable, results demonstrate that gender $(\mathrm{r}=-.11, p<.01)$, and education $(\mathrm{r}=-.16, p<.01)$ were significant inverse correlates of age. However, marital status $(\mathrm{r}=.38, p<.01)$ was a positive correlate of life satisfaction. This positions age as a possible moderator for the socio-demographic predictors of life satisfaction.

The hierarchical moderated multiple regression analysis was used to test the moderating effect of age on the relationship between socio-demographic variables and life satisfaction. To facilitate interpretation of significant interactions, some $5 \times 5$ interaction tables and graph were plotted to show the moderation effect, where applicable. 
Table 2. The summary of moderated hierarchical multiple regression analysis of the influence of socio-demographic factors on life satisfaction

\begin{tabular}{|c|c|c|c|c|c|}
\hline \multirow[b]{3}{*}{ Predictors } & \multicolumn{3}{|c|}{ STEP } & \multicolumn{2}{|l|}{ STEP } \\
\hline & \multicolumn{2}{|r|}{1} & \multicolumn{3}{|c|}{2} \\
\hline & $\mathrm{B}$ & t-value & Sig. B & t-value & Sig. \\
\hline Age & -.121 & -3.496 & $<.01-.129$ & -3.584 & $<.01$ \\
\hline Sex & -.043 & -1.327 & $>.05-.051$ & -1.541 & $>.05$ \\
\hline Marital status & .093 & 2.659 & $<.01 .063$ & 1.551 & $>.05$ \\
\hline Education & .054 & 1.686 & $>.05 .053$ & 1.640 & $>.05$ \\
\hline $\mathrm{Age}^{*}$ sex & & & -.051 & -1.499 & $>.05$ \\
\hline Age.*Marital Status & & & .080 & 1.983 & $<.05$ \\
\hline Age*Education & & & -.004 & -.114 & $>.05$ \\
\hline $\mathbf{R}$ & & .13 & & .15 & \\
\hline $\mathbf{R}^{2}$ & & $.018 *$ & & $.023 * *$ & \\
\hline$\Delta \mathbf{R}^{2}$ & & $.02 *$ & & .005 & \\
\hline F-RATIO & & $4.61 * *$ & & $3.39 * *$ & \\
\hline
\end{tabular}

The result from Table 2 reveals that age, gender, marital status and educational qualification jointly and significantly predicted life satisfaction $(F(1,1007)=4.61, p<.001)$. The $r^{2}$ value of 0.05 shows that the predictor variables contributed about $5 \%$ to life satisfaction. The independent influence of the predictor variables shows that of age and marital status independently and significantly influenced life satisfaction $(\beta=-0.12, \mathrm{t}=-3.50, \mathrm{p}<.01 ; \beta=-10$, $\mathrm{t}=2.65, \mathrm{p}<.05$ ) respectively. However, sex and educational qualification were not significant. Also, the independent influence of the predictor variables shows that age and interaction of age and marital status predicted life satisfaction $(\beta=-0.13, \mathrm{t}=-3.58, \mathrm{p}<.01 ; \beta=-0.08, \mathrm{t}=1.98$, $\mathrm{p}<.05)$ respectively. The moderated relationship between age and marital status contributed significant $0.5 \%\left(\mathrm{R}^{2}=.15, \Delta \mathrm{R}^{2}=.005, \mathrm{~F}(1,1004)=3.39, p<.01\right)$ increase in the prediction of life satisfaction and size of the co-efficient of determination in the model. The correction term for the moderated relationship between marital status and life satisfaction was significant ( $\mathrm{ct}=0.08, \mathrm{t}=1.98, \mathrm{p}<.01$ ). A breakdown of the moderation effect was carried-out using a $5 \times 5$ interaction graph presented in fig 1 : 


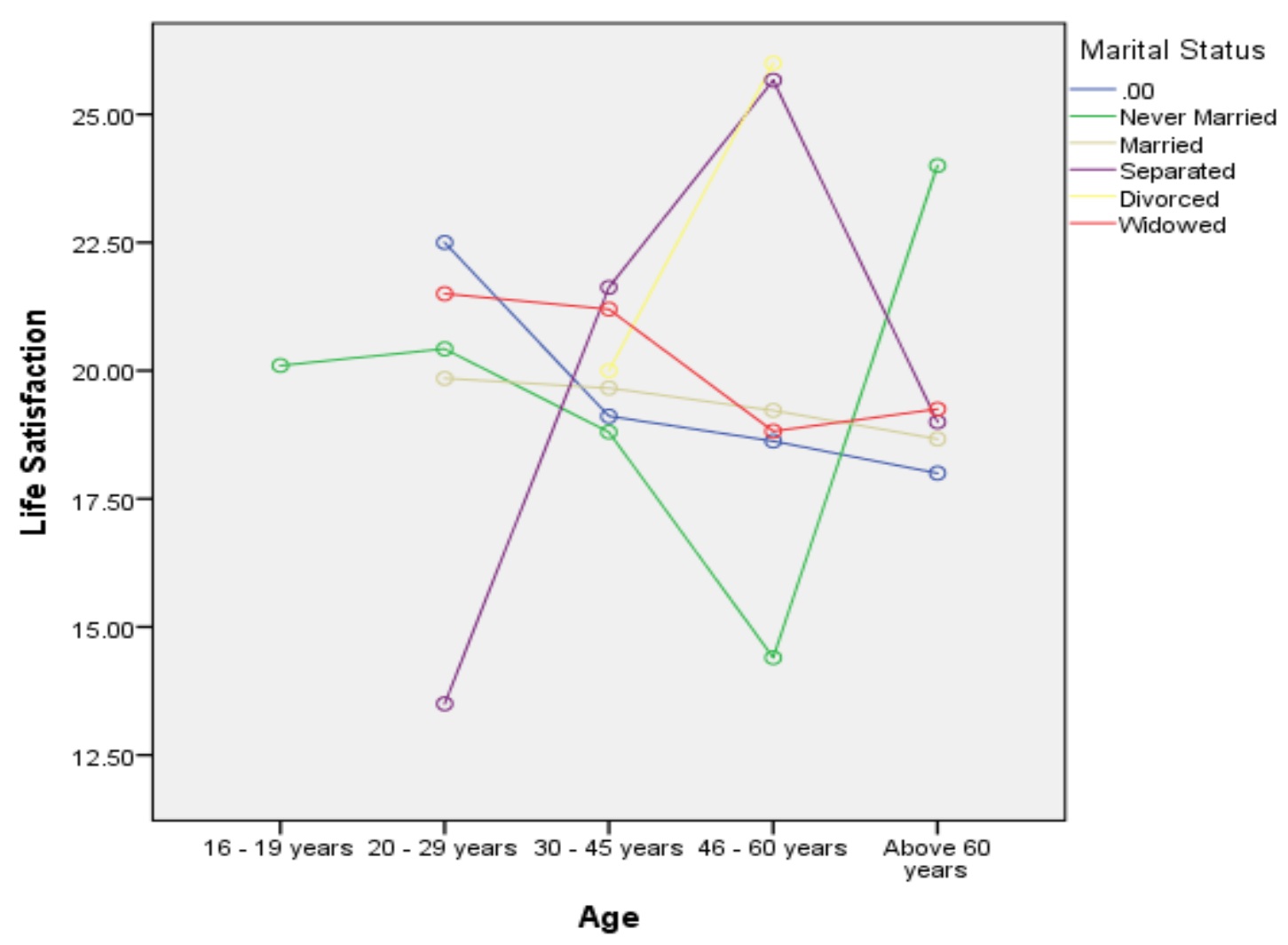

Non-estimable means are not plotted

Figure 1. The interaction effect of age and marital status on life satisfaction

The graph reveals that younger participants (below 30years) who were divorced or widowed or never married were more satisfied with life than those respondents that were married or separated. Similarly, respondents (between 30-60 years) who were divorced or widowed or never married were more satisfied with life than those that were married or separated. Also, respondents above 60 years of age who were never married were more satisfied with life than those married, divorced, separated or single.

\section{Discussion}

The first hypothesis was confirmed. The findings reveal that age, gender, marital status and educational qualification jointly and significantly predicted life satisfaction. This result is consistent with the previous studies that have reported positive association between socio-economic factors and life satisfaction. Sacks, Stevenson and Wolfers (2010) and Aldousari and Kassouf (2010) document a positive relationship between subjective wellbeing and education, income and social relationships. Similarly, Frey (2008) found demographic variables like, income, marriage, education and religiousity to be significantly associated with individual happiness.

The independent influence of the predictor variables reveals that age and marital status 
independently and significantly influenced life satisfaction. This outcome is in line with the conclusion of Charles and Carstensen(2009) who argue that individuals experience more life satisfaction as age increases because, as time goes by, older people become aware of mortality and therefore spend more time in activities that contribute to their immediate well-being rather than pursuing goals that are meant for the future. The significant independent influence of marital status on subjective wellbeing is in agreement with the study of Musick \& Bumpass,(2012) who found marriage to be linked with adult psychological well-being. In western countries, numerous studies have confirmed that married and cohabiting individuals were more likely to report greater life satisfaction than their unmarried, divorced, and widowed counterparts (Soons, Liefbroer, \& Kalmijn, 2009; Musick \& Bumpass, 2012).

However, gender and educational qualification did not significantly influence subjective wellbeing. The insignificant outcome of gender influence is consistent with previous findings by Casas, Figuer, Gonzalez, Malo, Alsinet and Subarroca (2007) and Froh, Yurkewicz and Kashdan (2009). They conclude there was no difference in the level of life satisfaction across gender. The insignificant result of educational qualification is in conformity with Salinaz-Jimenez, Aartes and Salinaz-Jimenez (2011) who conclude that the negative relationship between educational attainment and life satisfaction is explained by the tendency of the highly educated individuals to have greater job expectations and personal ambitions than the less educated and if such expectations fail, it may lead to a decline in life satisfaction. Generally, the negative association between education and life satisfaction is usually explained in terms of relative deprivation, the well educated expecting more than they get. The knowledge and exposure that comes with education encourage more ambition and higher achievement targets and subsequently more stress which might lead to dissatisfaction for the highly educated people.

The second hypothesis was also confirmed. The result demonstrates that age interacted with marital status to influence subjective wellbeing. The interaction graph reveals that younger participants who were below the age of 30years, who were divorced or widowed or never married were more satisfied with life than participants who were married or separated. This is consistent with the previous findings by Blanchflower and Oswald (2008) and Steptoe, Deaton \& Stone,(2015) who report that life satisfaction reduces with age in lower-income and middle-income countries. Baird, Lucas and Donnellan (2010) contend that there is a longitudinal decrease in life satisfaction from age 70 and above. Gerstorf, Ram, Roecke, Lindenberger and Smith (2008) confirm there is a great reduction in life satisfaction about 2 or 3 years before death. Despite the report that old people possess the ability to adapt and manage their circumstances. such ability often reduces among the very old people. Gwozdz and Sousa-Poza, (2010) note that there is a significant reduction in subjective wellbeing among the oldest old. The implication of this is that subjective wellbeing in old age may only occur in old people, in early old age.

Further analysis also reveals that participants between ages 30 and 60 years, who were divorced or widowed or never married were more satisfied with life than those that were married or separated. Also, participants above 60 years of age who were never married were more satisfied with life than those married, divorced, separated or single. The implication is 
that married participants reported lower levels of subjective wellbeing compared to the singles, never married, divorced and widowed. Although several studies have supported the claim that marriage is related to happiness and life satisfaction, many recent studies have reported contrary findings. This result conforms with studies such as; Proulx, Helms, \& Buehler, (2007), Dush, Taylor, \& Kroeger, (2008), Luhmann, Hofmann, Eid, \& Lucas, (2012) and Carr, Freedman, Cornman \& Schwarz, (2014). These researchers argue that what makes married people satisfied with life is not the marriage itself but the quality of the marriage. They suggest that a problematic marriage is not capable of guaranteeing happiness. Similarly, Bookwala, (2012) observe that individuals' overall life satisfaction is influenced by their satisfaction with their marriages. Longitudinal studies have also shown that as marital quality decreases, depression increases (Karney, 2001; Proulx \& colleagues, 2007). In addition, Gere \& Schimmack, (2011) have also identified conflict between partners as a major cause of lower subjective well-being. This argument seems logical, considering the findings of Reblin, Uchino and Smith (2010) which link negative relationships with weak or ineffective social support and a source of stress (Holt-Lunstad, Uchino, Smith, \& Hicks, 2007). Evidently, recent studies are in support of marital quality being positively related to subjective wellbeing, however, Bookwala, (2012) and Jackson, Miller, Oka, \& Henry, (2014) contend that the relationship between marital quality and subjective wellbeing is usually stronger among women than men.

\subsection{Conclusion}

The findings reveal that age, gender, marital status and educational qualification jointly and significantly predicted subjective wellbeing. This study found no main effect of gender and educational qualification on subjective wellbeing and no significant interaction effect of age/gender and age/educational qualification but there was a significant main effect of age and marital status on subjective wellbeing. The result further demonstrates the interaction effect of age and marital status on subjective wellbeing.

\subsection{Implication and Recommendation}

The result of this study has indicated both the joint predictive strength as well as the the main and interaction effect of age, gender, marital status and educational qualification on subjective wellbeing. This emphasizes the significance of socio-demographic factors in the assessment and eventual improvement of subjective wellbeing. This result has implications for clinical practices especially as it relates to counseling. Some of the socio-demographic characteristics appear to be factors of the environment rather than being innate. They appear to be behaviours that could be learnt and achieved through counseling and reinforcement to individuals lacking in those aspects of life. Socio-demographic factors such as marriage, education, relationships and so on, should be included in counseling.

It is therefore recommended that subjective wellbeing experts and researchers generally, should include numerous socio-demographic factors that could possibly predict subjective well being in order to have a comprehensive assessment of the relationship between socio-demographic characteristics and subjective wellbeing. 


\section{Acknowledgements}

My great appreciation first goes to the almighty God for the ability to complete this study. I am extremely grateful to Professor A.M. Sunmola for his mentoring and constructive suggestions through out the course of this work. My profound gratitude is also extended to Dr. A.I.Alarape for his expertise and assistance in the area of statistical analysis. Finally, my deepest gratitude goes to my beautiful wife, Biola and my lovely children; Tito,Tobi and Tumi for always being there for me and providing all the necessary support, cooperation and motivation for the duration of this study.

\section{References}

Agbo, A. A., Nzeadibe, T. C., \& Ajaero, C. K. (2012). Happiness in Nigeria: A socio-cultural analysis. In H. Selin \& G. Davey (Eds.), Happiness across cultures: Views of happiness and quality of life in non-Western cultures. New York: Springer.

Aldousari, S., \& Kassouf, W. (2010). Update on the management of non-muscle invasive bladder cancer. Can Urol Assoc Journal, 4, 56-64. https://doi.org/10.5489/cuaj.777

Alesina, A., Di Tella, R., \& MacCulloch, R. (2004). Inequality and happiness: are Europeans and Americans different? Journal of Public Economics, 88(9), 2009-2042. https://doi.org/10.1016/j.jpubeco.2003.07.006

Baird, B. M., Lucas, R., \& Donnellan, M. B. (2010). Life satisfaction across the lifespan: Findings from two nationally representative panel studies. Soc Ind Res, 99, 183-203. https://doi.org/10.1007/s11205-010-9584-9

Blanchflower, D. G., \& Oswald, A. J. (2008). Is well-being U-shaped over the life cycle? Soc Sci Med., 66, 1733-1749. https://doi.org/10.1016/j.socscimed.2008.01.030

Blanchflower, D. G., \& Oswald, A. J. (2011). International happiness: a new view on the measure of performance. Acad Manage Perspect, 25, 16-22. https://doi.org/10.3386/w16668

Boarini, R., Comola, M., Smith, C., Manchin, R., \& de Keulenaer, F. (2012). What Makes for a Better Life?: The Determinants of Subjective Wellbeing in OECD Countries - Evidence from the Gallup World Poll, OECD Statistics Working Papers, 2012/03, OECD Publishing.

Bond, J., \& Corner L. (2004). Quality of life and older people. Open University Press.

Bookwala, J. (2012). Marriage and other partnered relationships in middle and late adulthood. In R. Blieszner, \& V. H. Bedford (Eds.), Handbook of aging and the family (pp. 91-124). Santa Barbara, CA: ABC-CLIO.

Carr, D., \& Springer, K. W. (2010). Advances in families and health research in the $21 \mathrm{st}$ century. Journal of Marriage and Family, 72, 743-761. https://doi.org/10.1111/j.1741-3737.2010.00728.x

Carr, D., Freedman, V. A., Cornman, J. C., \& Schwarz, N. (2014). Happy marriage, happy life? Marital quality and subjective well-being in later life. Journal of Marriage and Family, 76(5), 930-948. https://doi.org/10.1111/jomf.12133 
Carstensen, L. (1991). Socioemotional selectivity theory: Social activity in life-span context. Annual Review of Gerontology and Geriatrics, 11, 195-217.

Casas, F., Figuer, C., Gonzalez, M., Malo, S., Alsinet, C., \& Subarroca, S. (2007). The well-being of 12-to16-year old adolescents and their parents: Results from 1999 to 2003 Spanish samples. Social Indicators Research, 83, 87-115. https://doi.org/10.1007/s11205-006-9059-1

Charles, S., \& Carstensen, L. (2009). Socio-emotional selectivity theory. In H. Reis \& S. Sprecher (Eds.), Encyclopedia of human relationships, 1578-1581. Thousand Oaks: Sage Publications.

Cheng S. (2004). Age and subjective well-being revisited: A discrepancy perspective. Psych Ageing, 19(3), 409-415. https://doi.org/10.1037/0882-7974.19.3.409

Cu-ado, J., \& De Gracia, F. P. (2012). Does education affect happiness? Evidence for Spain. Social Indicators Research, 108, 185-196. https://doi.org/10.1007/s11205-011-9874-x

Diener E., \& Suh, E. (1998). Age and subjective well-being: An international analysis. Ann Rev Geron Ger., 17, 304-324.

Diener, E., Suh, E. M., Lucas, R. E., \& Smith, H. L. (1999). Subjective well-being: Three decades of progress. Psychological Bulletin, 125(2), 276-302. https://doi.org/10.1037/0033-2909.125.2.276

Diener, E., \& Diener, M. (1995). Cross-cultural correlates of life satisfaction and self-esteem. Journal of Personality and Social Psychology, 68, 653-663. https://doi.org/10.1037/0022-3514.68.4.653

Dush, C. M. K., Taylor, M. G., \& Kroeger, R. A. (2008). Marital happiness and psychological well-being across the life course. Family Relations, 57, 211-226. https://doi.org/10.1111/j.1741-3729.2008.00495.x

Easterlin, R. A. (2003). Happiness of women and men in later life: Nature, determinants, and prospects. In Advances in quality-of-life theory and research (pp. 13-25). Springer Netherlands. https://doi.org/10.1007/978-94-017-0387-1_2

Eurofound. (2013a). Third European Quality of Life Survey - Quality of life in Europe: Subjective Well-Being, Publications Office of the European Union, Luxembourg). Women, men and working conditions in Europe, The fifth European Working Conditions Survey (EWCS). Publications Office of the European Union,

Frey, B. (2008). Happiness: a revolution in economics. Cambridge: MIT Press.

Frey, S., \& Stutzer, A. (2002). What can economists learn from happiness research? Journal of Economic Literature, 40, 402-435. https://doi.org/10.1257/jel.40.2.402

Frijters, P., \& Beatton, T. (2012). The mystery of the U-shaped relationship between happiness and age. $J$ Econ Behav Organ., 82(2-3), 525-542. https://doi.org/10.1016/j.jebo.2012.03.008 
Froh, J. J., Yurkewicz, C., \& Kashdan,T. B. (2009). Gratitude and subjective well-being in early adolescence: Examining gender differences. JournalofAdolescence, 32, 633-650.

George, L. K. (2006). Perceived quality of life. In: Binstock RH, George LK (eds). Handbook of Aging and the Social Sciences. San Diego: Academic Press, 320-336. https://doi.org/10.1016/B978-012088388-2/50021-3

Gere, J., \& Schimmack, U. (2011). When romantic partners' goals conflict: Effects on relationship quality and subjective well-being. Journal of Happiness Studies, 14, 37-49. https://doi.org/10.1007/s10902-011-9314-2

Gerstorf, D., Ram, N., Roecke, C., Lindenberger, U., \& Smith, J. (2008). Decline in life satisfaction in old age: Longitudinal evidence for links to distance-to-death. Psychol Aging, 23(1), 154-168. https://doi.org/10.1037/0882-7974.23.1.154.

Goldbeck, L., Schmitz, T. G., Besier, T., Herschbach, P., \& Henrich, G. (2007). Life satisfaction decreases during adolescence. Quality of Life Research, 16, 969-979. https://doi.org/10.1007/s11136-007-9205-5

Graham, C., \& Chattopadhyay, S. (2013). Gender and wellbeing around the world. Int. J. Happiness and Development, 1(2), 212-232. https://doi.org/10.1504/IJHD.2013.055648

Gwozdz, W. \& Sousa-Poza, A. (2010). Ageing, health and life satisfaction for the oldest old: an analysis for Germany". Social Indicators Research, 397-417. https://doi.org/10.1007/s11205-009-9508-8

Hansen, T., \& Slagsvold, B. (2011). Alder. In S. Næss, T. Moum \& J. Eriksen (eds). Livskvalitet. Forskning om det gode liv. (pp. 37-154). Bergen: Fagbokforlaget.

Hansen, T., \& Slagsvold, B. (2012). The age and subjective well-being paradox revisited: A $\begin{array}{llll}\text { multidimensional } & \text { perspective. } & \text { Norsk }\end{array}$ https://doi.org/10.5324/nje.v22i2.1565

Healmes, E., Chrisjohn, R. D., \& Goffin, R. D. (1998). Confirmatory factor analysis of the life satisfaction index. Social Indicators Research, 45, 371-390. https://doi.org/10.1023/A:1006966419159

Helliwell, J. F. (2003). How's life? Combining individual and national variables to explain subjective well-being. Econ Model, 20, 331-360. https://doi.org/10.1016/S0264-9993(02)00057-3

Helliwell, J. F. (2008). Life satisfaction and quality of development. Retrieved from http://www.nber.org/papers/w14507.pdf. https://doi.org/10.3386/w14507

Holt-Lunstad, J., Uchino, B. N., Smith, T. W., \& Hicks, A. (2007). On the importance of relationship quality: The impact of ambivalence in friendships on cardiovascular functioning. Annals of Behavioral Medicine, 33, 1-12. https://doi.org/10.1007/BF02879910

House, J. S., Landis, K. R., \& Umberson, D. (1988). Social relationships and health. Science, 241, S40-S45. https://doi.org/10.1126/science.3399889 
Iveniuk, J., Waite, L. J., Laumann, E., McClintock, M. K., \& Tiedt, A. D. (2014). Marital conflict in older couples: Positivity, personality, and health. Journal of Marriage and Family, 76, 130-144. https://doi.org/10.1111/jomf.12085

Jackson, J.B., Miller, R.B. Oka, M., \& Henry, R.G. (2014).Gender differences in marital satisfaction: A meta-analysis. Journal of Marriage and Family, 76, 105-129. https://doi.org/10.1111/jomf.12077

Kahneman, D., \& Krueger, A.B. (2006). Developments in the measurement of subjective well-being. The Journal of Economic Perspectives, 20(1), 3-24. https://doi.org/10.1257/089533006776526030

Kapteyn, A., Smith, J. P., \& Van Soest, A. (2009). Comparing life satisfaction.

Karney, B. R. (2001). Depressive symptoms and marital satisfaction in the early years of marriage: Narrowing the gap between theory and research. In S. R. H. Beach (Ed.), Marital and family processes in depression: A scientific foundation for clinical practice (pp. 45-68). Washington DC: American Psychological Association.

Klasen, S. (2004). Gender-Related Indicators of Well-Being, Discussion Papers / Universitat Gottingen, Ibero-Amerika-Institut für Wirtschaftsforschung, No. 102.bourg.m937-en

Lucas, R. E., Clark, A. E., Georgellis, Y., \& Diener, E. (2003). Reexamining adaptation and the set point model of happiness: Reactions to changes in marital status, 84(3), 527-539.

Luhmann, M., Hofmann, W., Eid, M., \& Lucas, R. E. (2012). Subjective well-being and adaptation to life events: A meta-analysis. Journal of Personality and Social Psychology, 102.

Luong, G., \& Charles, S.T., \& Fingerman, S.L. (2011). Better with age: Social relationships across adulthood. Journal of Social and Personal Relationships, 28, 9-23.

Mayungbo, O.A. (2016). Agreeableness, Conscientiousness and Subjective Wellbeing. PEOPLE: International Journal of Social Sciences, 2(3), 68-87. https://dx.doi.org/10.20319/pijss.2016.23.6887

Moksnes, U. K., \& Espnes, G. A. (2013). Self-esteem and life satisfaction in adolescents-gender and age as potential moderators. Quality of Life Research, 22, 2921-2928. https://doi.org/10.1007/s11136-013-0427-4

Mousavi, M., Shiani, M., Mohammadi, M.A. (2011). Sadjadi H, Tabatabaee F, Assari S. Life satisfaction in Iran: a national representative study. Sci Res Essays, 6, 1839-1844.

Musick, K., \& Bumpass, L. (2012). Reexamining the Case for Marriage: Union Formation and Changes in Well-being. Journal of Marriage and Family, 74(1), 1-18. https://doi.org/10.1111/j.1741-3737.2011.00873.x

Neugarten, B. L., Havighurst, R. J., \& Tobin, S. S. (1961). The measurement of life satisfaction. Journal of Gerontology, 16, 134-143. https://doi.org/10.1093/geronj/16.2.134

Nordbakke, S., \& Schwanen, T. (2013). Well-being and mobility: A theoretical framework 
and literature review focusing on older people. Mobilities, 9(1), 104-129. https://doi.org/10.1080/17450101.2013.784542

Oladipo, S. E., \& Olapegba, P. O. (2012). Evidence of low life satisfaction among ndergraduates in Southwest Nigeria. Paper presented at the International Conference of Psychologists, South Africa.

Proulx, C. M., Helms, H. M., \& Buehler, C. (2007). Marital quality and personal well-being: A meta-analysis. Journal of Marriage and Family, 69, 576-593. 592-615. https://doi.org/10.1111/j.1741-3737.2007.00393.x

Reblin, M., Uchino, B. N., \& Smith, T. W. (2010). Provider and recipient factors that may moderate the effectiveness of received support: Examining the effects of relationship quality and expectations for support on behavioral and cardiovascular reactions. Journal of Behavioral Medicine, 33, 423-431. https://doi.org/10.1007/s10865-010-9270-z

Sacks, D. W., Stevenson, B., \& Wolfers, J. (2010). Subjective well-being, income, economic development and growth.

Salinaz-Jimenez, M. M., Aartes, J. Y., \& Salinaz-Jimenez, J. (2011). Education as a Positional Good: A Life Satisfaction Approach. Social Indicators Research, 103(3), 409-426. https://doi.org/10.1007/s11205-010-9709-1

Schilling, O. (2006). Development of life satisfaction in old age: Another view on the "Paradox". Soc Ind Res, 75(2), 241-271. https://doi.org/10.1007/s11205-004-5297-2

Soons, J. P. M., Liefbroer, A. C., \& Kalmijn, M. (2009).The Long-Term Consequences of Relationship Formation for Subjective Well-Being. Journal of Marriage and Family, 71(5), 1254-70. https://doi.org/10.1111/j.1741-3737.2009.00667.x

Steptoe, A., Deaton, A., \& Stone, A. A. (2015). Subjective wellbeing, health, and ageing. Lancet, 385, 640-648. https://doi.org/10.1016/S0140-6736(13)61489-0

Strine, T. W., Chapman, D. P., Balluz, L. S., Moriarty, D. G., \& Mokdad, A. H. (2008). The associations between life satisfaction and health-related quality of life, chronic illness, and health behaviors among U.S. community-dwelling adults. J Community Health, 33, 40-50. https://doi.org/10.1007/s10900-007-9066-4

Sun, S., Chen, J., Johannesson, M., Kind, P., \& Burström, K. (2016). Subjective well-being and its association with subjective health status, age, sex, region, and socio-economic characteristics in a Chinese population study. $J$ Happiness Stud., 17, 833-873. https://doi.org/10.1007/s10902-014-9611-7

Tesch-Romer, C., Motel-Klingebiel, A., \& Tomasik, M. J. (2008). Gender differences in subjective well-being: Comparing societies with respect to gender equality. Social Indicators Research, 85(2), 329-349. https://doi.org/10.1007/s11205-007-9133-3

Ulloa, B. F. L., Møller, V., \& Sousa-Poza, A. (2013). How does subjective well-being evolve with age? A literature review. Journal of Population Ageing, 6(3), 227-246. 
https://doi.org/10.1007/s12062-013-9085-0

Umberson, D., \& Chen, M. (1994). Effects of a parent's death on adult children: Relationship salience and reaction to loss. American Sociological Review, 59, 152-168. https://doi.org/10.2307/2096138

Umberson, D., Williams, K., Powers, D.A., Liu, H., \& Needham, B. (2006). You make me sick: Marital quality and health over the life course. Journal of Health and Social Behavior, 47, 1-16. https://doi.org/10.1177/002214650604700101

United Nations. (2012). World Happiness Report. Helliwell, J., Layard, R. and Sachs, J., eds., The Earth Institute, Columbia University.

Veenhoven, R. (1994). Is happiness a trait? Social indicators research, 32(2), 101-160. https://doi.org/10.1007/BF01078732

Veenhoven, R. (2009). How do we assess how happy we are? Tenets, implications and tenability of three theories. In A. K. Dutt \& B. Radcliff (eds). Happiness, economics and politics: towards a multi-disciplinary approach (pp. 45-69). United Kingdom: Edward Elger Publishers. https://doi.org/10.4337/9781849801973.00009

Veenhoven, R. (1993). Happiness in Nations: Subjective Appreciation of Life in 56 Nations 1946-1992. Erasmus University Press, Rotterdam.

Verbakel, E. (2012). Subjective Well-Being by Partnership Status and its Dependence on the Normative Climate. European Journal of Population, 28(2), 205-232. https://doi.org/10.1007/s10680-012-9257-2

Waite, L., \& Gallagher, M. (2000). A case for marriage. New York: Doubleday.

Zweig, J. S. (2015). Are women happier than men? Evidence from the Gallup World Poll. Journal of Happiness Studies, 16(2), 515-541. https://doi.org/10.1007/s10902-014-9521-8

\section{Copyright Disclaimer}

Copyright for this article is retained by the author(s), with first publication rights granted to the journal.

This is an open-access article distributed under the terms and conditions of the Creative Commons Attribution license (http://creativecommons.org/licenses/by/3.0/). 